\title{
Exploration of building multi-dimensional innovation practical platform to cultivate energy chemical engineering students' innovation ability
}

\author{
Xiu Chen, Yongbin Lai ${ }^{*}$, Xiaolin Chen, Mingqiang Chen \\ Anhui University of Science \& Technology, Anhui Huainan, China \\ Corresponding Author: Yongbin Lai
}

Keywords: Innovation; Practice; Talent Development; Energy Chemical Engineering.

\begin{abstract}
Depending on the innovation ability cultivation of students who major in energy chemical engineering in Anhui University of Science and Technology, this paper illustrates the connotation of multi-dimensional innovation practical platform. It puts forward building contents, as well as the goals, and also discusses the implementation plans. The effect of the practical platform in the cultivation is defined in this paper, especially its reference function for talent development in other majors.
\end{abstract}

\section{Introduction}

In 2010, China approved the setting of some strategic and new-developing undergraduate majors in order to meet the urgent needs of high quality talents. As one of the majors, "energy chemical engineering" aims to meet the needs of new energy industry and solve the problems of technical talents demand during the development of new energy industry. For example, renewable energy technology, clean energy conversion, new energy utilization, coal chemical industry, environmental catalysis, green synthesis, etc. This major focus on developing advanced practical talents who have good scientific literacy, solid foundation, board knowledge, creative spirits, practical ability and international perspective to achieve social sustainable development in the future. Higher education is the main method of knowledge innovation, diffusion and application. Universities and colleges are the cradle of cultivating innovation spirits and talents. Only constant innovation can Chinese nation achieve sustainable development and strong the country. Hence, enhancing undergraduates' innovation ability becomes a new demand for Chinese universities and colleges.

It is well known that study is a process of "practicing, cognizing and re-practicing". Higher education also needs to follow the laws of epistemology. It teaches basic theories in class and consolidates the knowledge by practicing. Those basic theories can only be really understood through practice. Similarly, innovation ability, as a reflection of comprehensive quality, can only be improved by practice as well. Therefore, practice is the foundation of innovation education. Only if various practical platforms are built, the needs of cultivating undergraduates' innovation ability can be met.

Energy chemical engineering is very close to industrial demands as an applied subject. The needed talents must not only master the basic theories and advanced technology, but also have practical ability so that can easily get used to the industrial development. Coal chemical industry and clean energy are leading industries in Huainan, Anhui province which is filled with energy. This provides an unique opportunity for the innovation ability cultivation of students who major in energy chemical engineering in Anhui University of Science and Technology.

\section{Contents and goals of building multi-dimensional innovation practical platform}

Based on the current situation of innovation education in Chinese universities and the researches on achievements in foreign countries, building multi-dimensional practical platform is put forward combining with the developing situation of energy chemical engineering major in Anhui University of Science and Technology. The platform consists of 3 practical links: campus practice (experiments and curriculum design), off-campus practice (production practice) and college-enterprise interaction. 
By organic combination of the three links, the platform has become a multi-angled and multi-faceted one which intends to energy chemical engineering students. It contains campus lab, off-campus practical base and college-enterprise interaction center. The platform meets the demands of students' practice and innovation cultivation. Meanwhile, according to the idea of "taking students as the center, combining campus with off-campus, combining teaching and research", the platform regards college-enterprise interaction center as a link, then sets up operation mechanism, promotes orderly development, cultivates innovation ability and achieves common good among students, universities and enterprises.

\subsection{Contents}

Hardware construction of multi-dimensional innovation practical platform. Combining with the characteristics of energy chemical engineering major, the platform strengthens and regulates the existing production practical base outside campus. It realizes the connection between major and enterprise; expands new production practical base; enriches students' practice; optimizes resource allocation and management mechanism of lab; increases opening amounts and time of public and professional lab; guides and strengthens college-enterprise interaction; promotes orderly efficient operation and strengthens the bonds between college and enterprise.

Building of operation mechanism. The college and enterprise sign an agreement on working together to determine their duties and obligations, using the college-enterprise interaction center as the link. In detail, the mechanism found coordinate office; realize the coordination and assistance among lab, staff room and enterprise; perfect the practice; enhance students' understanding of the enterprise operation and industry development; improve their ability of applying professional knowledge.

\subsection{Goals}

By building multi-dimensional innovation practical platform, a reasonable high-quality teaching and scientific research team will be established. Making full use of the regional and subject advantages, the team will meet professionals' needs of innovation ability cultivation and further strengthen the coordination.

With the effective operation of the platform, universities will increase the proportion of practice, reform practical contents, perfect practical conditions and effectively improve energy chemical engineering students' innovation ability.

Meanwhile, cultivating excellent undergraduates under new situation and making them get used to society faster and better are also the goal of building such platform.

\section{Implementing Scheme of building multi-dimensional innovation practical platform}

The platform is a learning activity that inspires students to explore knowledge actively and solve problems by applying knowledge under the instructions of teachers. It realizes the concept of combining campus and off-campus, teaching and researches.

Regulate and enhance the building of staff room. The staff room must be built according to teacher's specialty and research area. Define the goals of evaluation. Support undergraduates to join teams, projects and activities actively. Enhance communication between staff room and enterprise. Make teaching and research promote each other.

Strengthen the management of lab in campus. Regarding building integrative laboratory as the breakthrough, take the matching reform of teaching contents, curriculum design and production practice into consideration. Improve lab teachers' ability, give students autonomy and make the lab open for students.

Optimize the practice. In detail, consolidate existing production practical base and expand new base. Take individual differences into consideration, use various methods to give students instructions and choose teachers, places appropriately. Strengthen the effect of college-enterprise interaction center and promote development of subjects. 
Build perfect operating mechanism. Meet the demands of its development and promotion in order to serve technological innovation better.

Strengthen team building, adhere the guiding ideology that "people-centered", "serve teachers and students". Propose a new idea that is humanized and sustainable developed. Arouse the enthusiasm of teachers, ensure the cultivation of high-quality talents and promote education reform completely.

\section{Conclusion}

The suggestion that building multi-dimensional innovation practical platform for energy chemical engineering students in Anhui University of Science and Technology is put forward due to the good energy background in Anhui province. This decision meets the industrial need and combines subject characteristics. The implement will make practice in campus, practice off campus and college-enterprise interaction cooperate with each other, get mutual benefit, cultivate undergraduates' innovation ability, help them become more competitive and adaptable. Meanwhile, it has reference function for innovation cultivation in other majors and help build innovative country together.

\section{Acknowledgements}

Corresponding Author: Yongbin Lai, yblai@163.com.

This research was sponsored by Anhui Province Universities Provincial Quality Engineering Projects (Grant NO: 2015zy020 and 2016tszy030).

\section{References}

[1] Chen, Y.G. Han H.J. and Yang, J.L. 2013. "The Establishment and Practice of The Innovation Ability Training System for Undergraduate Students of Energy Chemical Engineering," Education Teaching Forum, (15):228-229.

[2] Liu, Q.Z. 2011. "Comprehensive Evaluation and Analysis of College Students' Innovative Quality," China Youth Study, (4):90-93.

[3] Wu, S.Q. 2007. "Deepening Higher Education Reform, Strengthening Innovation Capacity and Enhancing Innovative Talent Training," Tsinghua Journal of Education, 28(5):1-7.

[4] Tu, D.W. 2011. "Refrom and Practice of Practice Teaching based on Innovation Ability Training for Wood Science and Engineering Programming," China Educational Technology \& Equipment, (5):45-46.

[5] Li, Z.X. 2014. "A brief discussion on the way and platform for the cultivation of College Students' innovation ability," Journal of Hubei University of Economics (Humanities and Social Sciences), 11(1):120-121. 